\title{
O Estado Nacional-Socialista na ótica de Norbert Frei
}

\section{The National Socialist State in the view of Norbert Frei}

\author{
Marco Pais Neves dos Santos ${ }^{1}$
}

\begin{abstract}
Resumo
Este artigo tem como perspetiva enquadrante a II Guerra Mundial, o maior e mais sangrento conflito da história da humanidade, e trata a conceção do Estado Nacional-Socialista produzida por Norbert Frei, um dos mais influentes historiadores da atualidade, na sua obra: O Estado de Hitler: o poder nacionalsocialista de 1933 a 1945. Tem como objeto a forma como Norbert Frei concebe a história alemã, entre os anos de 1933-1945, e o seu olhar crítico sobre o Estado Nacional-Socialista, analisando-o não só do ponto de vista do crime ideológico, do darwinismo social, mas também através da história política e social, inclusive, questionando a participação e aceitação pela sociedade alemã da governação de Hitler, revelando que, apesar de ser um historiador natural da Alemanha, nunca esteve refém do passado e sempre procurou abrir o debate, contrariando a dificuldade de muitos alemães em recordarem o nazismo, para quem "a culpa alemã" de compactuar com o regime, sobretudo no holocausto, os levou a ocultarem durante algumas décadas o seu passado recente, inclusive nos circuitos intelectuais.
\end{abstract}

Palavra-chave: Norbert Frei. Hitler. Nacional-Socialismo. III Reich. Segunda Guerra Mundial.

\begin{abstract}
This article has as context World War II, the largest and bloodiest conflict in human history, and is the conception of the National Socialist State produced by Norbert Frei, one of the most influential historians of our time, in his work: The State of Hitler: The national Socialist power from 1933 to 1945. It has as object how Norbert Frei conceives German history between the years of 1933-1945, and his critical eye on the National Socialist State, analysing not only from the standpoint of ideological crime and Social Darwinism, but also through the political and social history, including questioning the involvement and acceptance by society of Hitler's German government, revealing that despite Norbert Frei was born in Germany, he has never been hostage to the past, and always sought to open the debate, countering the difficulty of many Germans to remember Nazism, for whom "German guilt" of a pact with the regime, especially in the Holocaust, led them to hide for a few decades their recent past, what includes the intellectual circuits.
\end{abstract}

Keywords: Norbert Frei. Hitler. National Socialism. III Reich. Second World War.

\section{Introdução}

A II Guerra Mundial, desencadeada pela Alemanha de Hitler, foi o maior e mais sangrento conflito da história da humanidade. Decorreu entre
1 de setembro de 1939 (invasão da Polónia) e 2 de setembro de 1945 (rendição do Japão) e envolveu os exércitos de 72 países. Foi disputada entre as maiores potências do mundo nos cinco continentes (direta

\footnotetext{
${ }^{1}$ Instituto da Construção e do Imobiliário (InCI) - Lisboa Portugal. Licenciatura em História pela Faculdade de Ciências Sociais e Humanas da Universidade Nova de Lisboa. Licenciatura em Geografia e Planeamento Regional pela Faculdade de Ciências Sociais e Humanas da Universidade Nova de Lisboa. Minor em Antropologia pela Faculdade de Ciências Sociais e Humanas da Universidade Nova de Lisboa. Mestre em Cidadania Ambiental e Participação pelo Departamento de Ciências e Tecnologia da Universidade Aberta. Email: marco.santos@inci.pt
} 
e indiretamente), provocou mais de 50 milhões de mortos, dos quais 7 milhões de deportados e milhões de vítimas com lesões físicas e psíquicas. Quando terminou, definiu a orientação política e econômica mundial das décadas seguintes (ZALOSA, 2009, p. 6). Emergiu de problemas políticos e territoriais não resolvidos na I Guerra Mundial, depois agravados pelo Tratado de Versalhes, ainda que, convém salientar, o recurso a armas para resolver conflitos (KEEGAN, 2006, p. 19), ou para dar continuidade a questões políticas (CLAUSEWITZ, 2003, p. 27), já é uma tradição antiga e não uma novidade da II Guerra Mundial.

O fascismo e o nacional-socialismo são filhos da guerra. Constituem primeiro um efeito da humilhação nacional perante a derrota. Traduzem também a desorientação de antigos combatentes que a guerra marcou profundamente e se sentiam estrangeiros no seu próprio país (TOUCHARD, 1991, p. 154).

A ideologia Hitleriana baseava-se num amontoado de ideias que incluem o niilismo de Nietzsche, o racismo de Gobineau e Chamberlain, a teoria da herança genética de Mendel, a fé no destino de Richard Wagner, a geopolítica de Haushofer e o neodarwinismo de Ploetz. As ideias impulsoras são o nacionalismo, o anticomunismo e o antissemitismo. Propõe a defesa do sangue e do solo alemão, o extermínio dos judeus, a subjugação dos povos europeus, o fortalecimento da raça ariana, a integração incondicional do indivíduo na comunidade e a fé cega no líder (Führer). Com base nessas linhas ideológicas, estabelece como objetivos políticos a construção de um novo Estado (o III Reich) e que seja capaz de promover a autonomia econômica para a Alemanha, libertá-la do "Diktat de Versalhes", conquistar o seu "espaço vital" e aniquilar o bolchevismo (PARKER, 1989 e 2006; TRAVERSO, 2002; GALLEGO, 2009; ZALOSA, 2009).

No início de 1920, nas funções de responsável pela propaganda do Partido Operário Alemão, que mais tarde viria a designar de Partido Operário Alemão
Nacional Socialista, vulgo Nazi, eram poucos os alemães que aplaudiam abertamente as pretensões de Adolf Hitler. No entanto, em 1922, já tinha como apoiantes figuras ilustres e era uma figura central da vida política de Monique (BRADLEY, 1990, p. 14), o que lhe deu força para tentar derrubar o governo do estado da Baviera (Putsch da Cervejaria, 1923). No entanto, o golpe falhou, acabou preso pela polícia bávara e foi condenado a uma pena de cinco anos de prisão, ainda que só tenha cumprido seis meses no estabelecimento prisional de Landsberg (1924); tempo que aproveitou para escrever Mein Kampf, obra publicada em 1925 (BRADLEY, 1990). O ato de tentar derrubar o governo mostrou que Hitler poderia ser alternativa à agonizante República de Weimar, mas a publicação do livro não teve a repercussão que Hitler desejaria, até porque esse livro representava para os alemães um trabalho irrealista de objetivos irrealizáveis, o que permite concluir que, nessa altura, ainda existia resistência às suas ideias.

No entanto, o agravamento das condições econômicas ao longo do período entre 1919/22 (hiperinflação) e 1929/32 (grande depressão), sobretudo após 1929, aumentou o descontentamento das classes mais "sacrificadas" pela crise, nomeadamente dos camponeses e da classe média (PARKER, 1989; CONZE et al., 2010). Ficava cada vez mais evidente, a incapacidade da República de Weimar, o que acontecia em contra ciclo com a popularidade de Hitler, em crescente expansão, o que muito se devia à sua poderosa capacidade de comunicar: ferramenta que utilizava para discursar em público ${ }^{2}$, em espetáculos de dimensão faraônica, com cenografia própria para cada ocasião, pensada ao pormenor e que permitiam influenciar, fascinar (tornou-se carismático) e inspirar a lealdade pessoal (BRADLEY, 1990; PARKER, 1989, 2006).

Hitler diferenciava-se pelo discurso determinado, destemido e convincente que empregava contra os malevolentes socialistas (sindicatos egoístas)

\footnotetext{
${ }^{2}$ Segundo Bradley (1990:14) “[...] a partir de 1922, realizava oito, dez, ou mesmo doze comícios políticos na mesma noite”.
} 
e exploradores capitalistas (baixos salários e desemprego), simultaneamente, incitando os alemães a elegerem-no como chanceler. Tratavase de uma tomada de posição diametralmente oposta à verificada da parte da insípida República de Weimar e dos seus defensores (EVANS, 1991, p. 97-118; CONZE et al., 2010). Por exemplo, em 1929, o discurso de Hitler apontava para soluções ditatoriais, como forma de resolver os problemas econômicos (BRADLEY, 1990), mas os alemães estavam tão oprimidos que ficavam maravilhados com a determinação de Hitler, pela forma como comunicava, e, cativados com as suas promessas (GALLEGO, 2009), negligenciavam a perda de liberdade implícita a uma situação política de ditadura (FREI, 2003, p. 57); estavam numa situação de total decadência onde tudo seria melhor do que aquilo que conheciam da débil República de Weimar.

Como forma de escape, sem que previssem que estavam a lançar as bases do que seria uma grande guerra europeia, que chamou a si países de todas as zonas do globo, os alemães foram ao encontro do apelo lançado por Hitler e este chegou ao poder em 1932, através de eleições livres. Ainda que, para essa situação, fossem determinantes o carisma e a popularidade nazi, conseguidas à custa de uma meticulosa gestão do quotidiano (aparecimento em público, preparação de locais de discurso, utilização de um sistema palavroso efusivo, etc.), bem como de alguma "ignorância" da parte do povo alemão (Parker, 1989) e intimidação e terror provocado pela SA $^{3}$ (TRAVERSO, 2002; GALLEGO, 2009), temos de aceitar a eleição de Hitler para o Reichstag (Parlamento) como um manifesto de insatisfação para com a República de Weimar, pelos anos de confusão e eleições sucessivas, e uma prova da aceitação das suas ideias por parte dos alemães (BRADLEY, 1990).

Na verdade, as ideias políticas de Hitler, tal como preconizadas no capítulo XI (Volk und Basse) de
Mein Kampf, procediam do mais puro darwinismo (TOUCHARD, 1991, p. 161), e não eram, de todo, as ideias da generalidade dos alemães, e inclusive ultrapassavam em muito a ávida vontade de revanche sustentada pelo povo alemão (contra os estrangeiros). No entanto, Hitler conseguiu gerir as suas ideias de forma exemplar, muitas vezes de forma oculta ou camuflada, ou controlando as emoções e os sentimentos dos alemães (GALLEGO, 2009), e estas acabaram por ser aceitas pela maioria, inclusive, Hitler foi considerado uma espécie de "Salvador da Pátria" (fé cega no Führer), o que se verificou até quase o final da guerra:

As atividades externas de Hitler foram aprovadas, pelo menos até 1941, porque os seus objetivos aparentes correspondiam aos objetivos da maioria dos alemães politicamente conscientes, apesar de os verdadeiros objetivos de Hitler irem muito mais longe do que isso: sair vitorioso de uma luta pela sobrevivência autoimposta (PARKER, 1991, p.12).

Com todo o poder proporcionado pela chefia suprema das forças armadas do Reich, derivado da fusão do cargo de Chanceler com o de Presidente (1934), Hitler conseguiu exponenciar em muito o normal negativismo de uma guerra (BRADLEY, 1990), ao ponto de Robert Alexander Clarke, historiador inglês, afirmar que "o conceito que a humanidade tinha de si nunca mais voltará a ser o mesmo" (JORDAN; WIEST, 2008, p. 95). Segundo Traverso (2002), a violência nazi era desumana mas não constituía totalmente uma novidade, porque, segundo o autor, representava a continuidade de um processo de desumanização e industrialização genocida originário da Europa liberal do século XIX (racismo de classe e genocídios coloniais).

Não obstante, as atrocidades hitlerianas terem marcado o mundo contemporâneo, inclusive os próprios alemães, porque, se, por um lado, colaboraram com o regime, por outro, foram vítimas desse mesmo regime. Ainda assim, os alemães são geralmente qualificados de culpados e não de

\footnotetext{
${ }^{3}$ Apesar de ter existido uma grande repressão, inclusive à "boca das urnas", que condicionou as eleições, a verdade é que Hitler granjeava a simpatia de um elevado número de alemães, e era provável que ganhasse as eleições, mesmo sem repressão.
} 
vítimas, tanto a título individual como coletivo, como se observa em algumas obras científicas mais recentes.

Neitzel e Welzer (2011), de forma muito documentada e fidedigna, com base em conversas gravadas entre soldados alemães mantidos prisioneiros durante a Guerra, comprovam que toda a sociedade alemã colaborava com as atrocidades do regime, pelo que, acreditamos nós, terá sido a consciência do erro que levou no pós-guerra, de forma propositada, o povo alemão a esquecer a figura de Hitler e a ocultar o Holocausto; visão que justifica o fato de, depois da II Guerra Mundial, não ter existido na Alemanha qualquer evento cultural relacionado com Hitler, nomeadamente até o ano de 2010, altura em que, pela primeira vez, foi realizada uma exposição sobre o enigma da popularidade de Adolf Hitler durante o Terceiro Reich. Aliás, só na primeira década do século XXI é que os alemães expressaram símbolos nacionalistas (ex. hastear a bandeira em residências particulares), sem que esse ato nacionalista fosse associado, ou remetido, ao período do Partido Nacional-socialista de Hitler (LEITE, 2010).

O incômodo dos alemães, quer seja por desilusão ou em sinal de vergonha (FREI, 2003, p. 226), verifica-se também na lei que proíbe a publicação de escritos nazistas, particularmente a difusão do livro de Hitler, Mein Kampf, considerado, por uns, uma espécie de guia ideológico e de ação nazista, que ainda influencia os neonazistas e, por outros, a "Bíblia Nazista" (por analogia à Bíblia Cristã). A região da Baviera, que detém os direitos editoriais da obra, tem feito de tudo para impedir a sua edição. Aliás, tudo faz para impedir qualquer publicação alusiva ao nacional-socialismo, tal como se verificou em 2009, quando a revista Zeitungszeugen, editada por Peter McGee, publicou extratos de um jornal nazista da época, intitulado o Völkischer Beobachter.

De acordo com Conze et al. (2010), os fatores mencionados anteriormente, demasiados punitivos para os alemães, nomeadamente a falta de emprego e as dificuldades financeiras (PARKER, 1989, p. 12), terão sido determinantes para o apoio da população alemã ao regime nacional-socialista, mas ainda assim os autores não isentam de culpas os alemães pelo "excesso de cumplicidade", sobretudo entre 1933 e 1945, e, por isso, consideram a sociedade alemã criminosa. De fato, nesse período, somente uma pequena franja da sociedade não apoiava o regime, mas, também, não se pronunciava, por receio de represálias. O grosso da população encarou a ideologia hitleriana como única e fundamental, seguiu o impulso do momento, mesmo que o fizesse sem preconceitos, por ingenuidade, e adotou uma política de denúncia, de colaboração com o regime, facilitando o trabalho à $\mathrm{SS}$, que passou a ter olhos e ouvidos em todo o território. Deve-se a este fator, a extrema eficácia da SS na captura de judeus, até porque tinha um reduzido número de efetivos. Ainda segundo Conze et al. (2010), a mesma culpa aplica-se às instituições alemãs que tentaram ocultar a participação ativa no extermínio de judeus, e dão como exemplo o Ministério Alemão do Exterior, considerado organização criminosa, por ter tido uma participação sintomática no extermínio dos judeus em toda a Europa, com base na diplomacia ${ }^{4}$.

Apesar da dificuldade alemã em lidar com as questões referentes à II Guerra Mundial, como vimos até o momento e continuaremos a ver nas páginas seguintes, Norbert Frei caracteriza o nacionalsocialismo, sem cair em radicalismos na obra $O$ Estado de Hitler: o poder nacional-socialista de 1933 a 1945, edição do editorial Notícias (2003). Aliás, nessa excelente obra, o próprio autor explora muito bem a cumplicidade e aceitação da sociedade alemã à governação de Hitler (FREI, 2003, p. 226227), o que a torna de eleição para este ensaio, onde vamos dar enfase à história política e social.

Neste trabalho, começamos com uma abordagem concisa ao autor e à contextualização da obra, de forma a permitir uma maior perceção da vida e obra

\footnotetext{
${ }^{4}$ Franz Rademacher ou Ernst von Weizsäcker são alguns dos diplomatas que intercedem junto do governo dos países onde estavam a prestar serviço no sentido de tentar "calar" os críticos ao regime de Hitler, como aconteceu com o escritor Thomas Mann.
} 
de Norbert Frei. A sua contextualização da obra incide sobre a evolução da historiografia alemã, antes, durante e depois do Terceiro Reich, tocando nas mentalidades que se formularam na Alemanha do pós-guerra e explorando com mais detalhe a posição de Norbert Frei, enquanto historiador do pós-guerra. Em seguida, através de uma perspetiva associativa, avaliativa e crítica, tentamos responder à indagação de como Norbert Frei caracteriza o Estado Social-Nacionalista? Para isso, começamos por identificar e explorar as linhas centrais da obra, que classificamos em quatro: origens do nazismo, formação do nazismo, consolidação do nazismo e radicalização do nazismo, onde focamos as manobras políticas realizadas por Adolf Hitler, coadjuvadas pela sociedade, que num só ano permitiram criar a "nova ordem" (ditatorial e draconiana), e concluímos, relacionando e integrando essa informação na resposta à questão de partida, deixando ainda espaço para uma concisa reflexão final, onde sintetizamos as questões mais importantes abordadas na obra e referidas ao longo do trabalho.

\section{O Autor e a Obra}

Norbert Frei nasceu na cidade alemã de Frankfurt em 1955.

Desde 2005, é Professor no Departamento de História Moderna e Contemporânea da Universidade Friedrich Schiller de Jena (FriedrichSchiller-Universität Jena) e, desde 2006, é Chefe do Centro de Jena - História do Século XX (Jena Center Geschichte des 20), que pertence ao Instituto de História da mesma Universidade.

O Centro de Jena possui enorme prestígio no campo da reflexão da História Contemporânea e destaca-se pela sua proeminente ação de fortalecer os laços entre a investigação e o ensino em nível internacional e interdisciplinar. É missão do Centro de Estudos reunir e trabalhar sobre as várias interpretações e perspetivas das pesquisas sobre a História do Século XX, com especial incidência sobre a História do Nacional-Socialismo e as suas consequências na Alemanha e na Europa, até o presente.

Para além das funções acadêmicas já mencionadas, o autor também foi membro de várias comissões e conselhos acadêmicos. Entre as funções mais recentes, de forma concisa, destacam-se: entre 1996 e 2003, membro e presidente do Conselho Consultivo do Instituto Fritz Bauer em Frankfurt; entre 1997 e 2005, foi membro do Conselho Consultivo Científico do Concurso Estudantil de História Alemã, para o prêmio do Presidente da República Federal (Bundespräsidenten), e, entre 1999 e 2002, foi membro da Comissão Independente para o Estudo da História da Bertelsmann no Terceiro Reich (Dritten Reich). Desde 1999, é membro consultivo do Instituto de História Alemã na Universidade de Tel Aviv e Presidente do Conselho da Administração da Fundação de Memoriais de Buchenwald e Dora-Mittelbau (Stiftung Gedenkstätten Buchenwald und MittelbauDora). Em 2005, assumiu funções de Presidente do Conselho Cientifico do Minerva de Koebner Centro de História Alemã da Universidade Hebraica de Jerusalém, funções que continua a exercer. Entre 2007/2008, dirigiu o Instituto Histórico FriedrichSchiller da Universidade de Jena e, no ano letivo (2010/11), cumpriu o Theodor Heuss, enquanto professor visitante na New School for Social Research, em Nova York. ${ }^{5}$

O título original da obra é "Der Führerstaat: Nationalsozialistische Herrschaft 1933 bis 1945”. Foi editada pela primeira vez em 1987 pela Deutscher Taschembuch Veriag. Posteriormente, foi atualizada e reeditada várias vezes (sempre por Norbert Frei). Em 2001, deu-se a sexta reedição, atualizada em conteúdos no âmbito das consequências mortíferas

\footnotetext{
${ }^{5}$ Programa criado em 1975, como o nome do Primeiro Presidente da Alemanha Ocidental após a II Guerra Mundial, que promove a união entre os intelectuais alemães e americanos.
} 
da ideologia racial nazista e dos contornos da população judaica da Europa. A versão portuguesa, de 2003, resultado da reedição do original de 2001, é, portanto, a mais atual.

À semelhança de outras obras do autor, tais como "Vergangenheitspolitik", "Hitlers Eliten nach 1945" ou "1945 und wir", o Estado de Hitler conjuga todas as propriedades de um bom livro de História. Possui um poderoso recheio analítico, sem cair em extravagância, uma escrita precisa, de fácil leitura, acessível a um público vasto e diversificado e não só o acadêmico. Respeita rigorosamente as normas científicas, está profundamente documentado e foi diligentemente estruturado. É de saudar esta particularidade porque nem sempre as obras científicas são acessíveis ao público de forma tão abrangente, apesar desta tradução apresentar muitos acrônimos e muitos termos em alemão que dificultam a leitura. ${ }^{6}$

É uma obra de grande mérito, sobretudo se contextualizada no percurso evolutivo da historiografia alemã, já que surgiu ainda na presença de uma geração de historiadores alemães que viveram a II Guerra Mundial, naturalmente reféns de um passado obscuro e pouco interessados em abrir o debate sobre o Nacional-Socialismo. É uma obra que aclara a posição de Norbert Frei, enquanto historiador do pós-guerra.

Estevão de Rezende Martins refere que, durante a primeira metade do século XX, entre os historiadores alemães, verificou-se uma grande persistência no método histórico tradicional, como resultado da conjuntura do desenvolvimento político-social que se vivia nesse período na Alemanha. Considera que os historiadores desse período tiveram "formação semelhante, de perfil humanístico, provindo de ambientes pequenos e identificando-se com projetos sociais e políticos da burguesia intelectual protestante" (Martins, 2007:49).

Não obstante, um regime político de gênese destruidora como foi o Nazismo, tem consequências de vários níveis, e a historiografia do século XX, na altura da Segunda Guerra Mundial, foi altamente condicionada pela ação nazi. A título de exemplo, um dos fundadores da Escola dos Annales, Marc Bloch, que militou na resistência francesa contra a ocupação nazi da França, foi detido e torturado pela $\mathrm{Gestapo}^{7}$, acabando fuzilado em 16 de junho de 1944

Durante o período da Alemanha nazi, tal como aconteceu em outros regimes ditatoriais, foi imposta à comunidade um modelo de vida que tinha de ser cumprido no supremo interesse da «comunhão nacional». A liberdade individual e os movimentos sindicais organizados desapareçam, a liberdade de expressão e a pluralidade de pensamento foram acessados e os partidos políticos extintos (à exceção do partido de Hitler). A repressão era uma constante, o Estado assumiu e determinou todas as regras e padronizou a sociedade, através do corporativismo.

Em todos os setores da sociedade, as consequências foram extremas e o mundo acadêmico não fugiu à regra, tendo sido formada uma nova historiografia sectária (do nacional-socialismo), sob a responsabilidade do Instituto do Reich para a História da Nova Alemanha, dirigido por Walter Frank. Esta ação provocou duas situações muito graves: primeiro, "não produziu nada de relevante para a historiografia crítica, na medida em que a historiografia estava a serviço de opções políticoideológicas, e cuja sustentação vincula o trabalho de pesquisa"; segundo, muitos dos historiadores que se exilaram passaram a dedicar-se somente à revisão da história alemã (MARTINS, 2007, p. 50-51).

\footnotetext{
${ }^{6}$ Situação considerada em nota dos tradutores: “ o tradutor manteve em alemão (em itálico) os nomes de organizações, departamentos, postos ou cargos cuja correspondência direta com nomes equivalentes em português fosse muito distante e discutível" (FREI, 2003, p. 7).

${ }^{7}$ A Gestapo, em alemão Geheime Staatspolizei, era a Polícia Secreta do Estado, e estava sob a administração geral da SS (Schutzstaffel).
} 
NorbertFrei surge assim comoum historiadorpóssegunda guerra que não está refém do passado, que procura abrir o debate sobre o Nacional-Socialismo e, sobretudo, procura desenvolver o conhecimento em nível internacional e interdisciplinar, ainda que o nazismo represente um assunto tabu na Alemanha, para uma grande parte da população e para uma grande parte de historiadores, principalmente para os que viveram durante a II Guerra Mundial.

A história produzida por Norbert Frei é objetiva e não estigmatizada, isto é, não assume como elemento central em estudo a decadência, perversidade ou o crime ideológico do nacionalsocialismo, principalmente depois de 1942, mas analisa a história política e social, mediante uma abordagem muito mais diferenciadora.

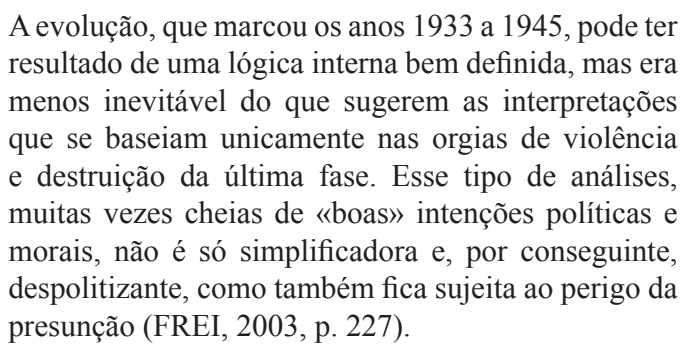

Não podemos negligenciar que muitos nazis, após o fim da guerra, voltaram a ter cargos públicos, com todo o estigma e represálias que isso representa, como se pode ler na citação seguinte:

\footnotetext{
En esta República Federal Alemana los juicios de los Aliados contra los nazis fueron muy poco efectivos, y el nuevo Estado alemán finalmente los protegió y amnistió. Muchos ex nazis estuvieron nuevamente al frente de sus funciones de otrora, cooperando en la construcción de una Alemania conservadora, democrática y capitalista, priorizando absolutamente la persecución de comunistas (ARIZALETA, 2010, citado por GONZÁLEZ, 2010, p. 12).
}

Para concluir, já em 1987, Norbert Frei aborda com objetividade o tema, quando lançou a primeira edição do Estado de Hitler, culpabilizando toda a sociedade alemã pela cumplicidade e aceitação da governação de Hitler, como se pode ler na seguinte citação:

Esse final silencioso constituía igualmente um sinal claro da sensação de culpa que as pessoas começavam a sentir. Não tinham acompanhado com entusiasmo o «Movimento», aplaudindo por demasiado tempo o Führer? O slogan «Ein Volk, ein Reich, ein Führer» (um povo, um império, um líder) não tinha sido uma realidade? De repente, afastados de doze anos de serviços políticos e ideológicos leais, e vendo-se órfãos do Führer, muitos começaram a lembrar-se do seu oportunismo pessoal e dos compromissos feitos com maior ou menor má consciência e perceberam que não sairiam ilesos dessa «grande época». O silêncio não era apenas a expressão de uma infinita desilusão e amargura, mas também um sinal de vergonha (FREI, 2003, p. 226, grifo nosso).

É um historiador que procura compreender o nacional-socialismo, sem cair em radicalismos, em abusos, em estigmatismos, fundamenta de forma precisa a informação que publica e sobretudo procura a evolução do conhecimento, aproximando a investigação do ensino a um nível interdisciplinar e internacional (ex. participação no programa Theodor Heuss).

\section{Interpretação das Linhas Centrais da Obra de Norberto Frei}

A obra focaliza o período de evolução do III Reich entre 1933 e 1945, dividindo esse período em três grandes fases do nacional-socialismo. Contudo, as linhas centrais da obra de Norbert Frei podem ser classificadas em quatro, representando a primeira o alicerce das restantes três, a saber: (1) origens do nazismo; (2) formação do nazismo; (3) consolidação do nazismo; e (4) radicalização do nazismo.

Linha 1 - Origens do Nazismo (1919 a 1933): são vários os argumentos que permitiram a chegada de Hitler ao poder, mas destaca-se a degradação econômica e social da Alemanha após a Primeira Guerra Mundial, as imposições do Tratado de Versalhes, a crise do capitalismo, fragilidade social (ex. a rotura do sistema financeiro e econômico destrói o emprego e gera desemprego, inflação, desvalorização da moeda, fome, frustração, etc.), o antissemitismo, o anticomunismo, a falta de opções da República de Weimar, o desejo de mudança de alguns setores da sociedade, a fundação do Partido 
Nacional-Socialista, dirigido por Adolf Hitler (para a população um líder carismático) e a tentativa fracassada do "Putsch" de Munique, que ainda mais reforçou a ideia de que Hitler era capaz de provocar a mudança que há muito era desejada na República de Weimar. Essa fase pode designar-se de Marcha do Nazismo ao poder e pode ainda ser fracionada em três subfases. A primeira entre 1919 e 1923 (fase fundacional), a segunda entre 1924 e 1928 (estabilização política) e a terceira de 1929/30 a 1933 (fase da grande expansão).

É interessante perceber que cada uma das fases políticas tem associada uma fase econômica, isto é, se analisarmos a evolução econômica da Alemanha, podemos perceber que entre 1919 e 1924 foi um período de hiperinflação, que entre 1924 e 1928/9 foi a fase de estabilização (o melhor período após a I Guerra Mundial que acabou com o Crash de 1929) e entre 1929 e 1933 a chegada ao poder de Hitler; portanto, a fase do desastre. Isto indica que foram sobretudo as condições econômicas que potenciaram os resultados eleitorais que levaram Hitler ao poder, nomeadamente, após o desastre econômico e financeiro americano, que fez com que o comércio caísse abruptamente (60\%), arrastando para a ruína o sistema bancário, a indústria, o comércio, logo os pequenos e grandes proprietários.

A República de Weimar não tinha soluções e assistia sem reação ao desmoronar da sociedade alemã. Estava totalmente dependente do financiamento americano, previsto no Plano de Dawes, negociado por Hjalmar Schacht com a Inglaterra e com um banqueiro Americano ${ }^{8}$, para poder assegurar o pagamento das reparações alemãs da Primeira Guerra Mundial, tal como advoga Couto e Hackl (2007, p. 311).

Com a queda de todo o sistema econômico, as fragilidades sociais aumentaram, o desespero aumentou e só o partido nazista indicava ter a força necessária, revolucionária, para acabar com inimigos internos, com os judeus e com os bolchevistas e com os inimigos externos, os responsáveis pelo Tratado de Versalhes. De fato, conseguiram isso, conforme se pode ler na citação a seguir:

É extraordinário o que o novo Reich tem conseguido realizar apenas no sector econômico! [...] Imaginese o que significa tomar conta, em janeiro de 1933, de um Estado que está à beira do colapso, com uma economia que há muito devia ter declarado falência, e depois, ao fim de muito pouco tempo, conseguir a recuperação, com esse mesmo Estado, com essa mesma economia, conseguir que milhões de pessoas voltassem ao trabalho e ganhassem agora o seu pão, criar um exército moderno e, ao mesmo tempo, através de enormes esforços, garantir o pão do nosso povo! (FREI, 2003, p.245).

Linha 2 - formação do nazismo (1933 a 1934): tal como aconteceu em todos os regimes totalitários, a primeira ação de Hitler foi restringir toda e qualquer fonte de contestação e, simultaneamente, fortalecer o seu poder, o que aconteceu logo em 1933/34, na formação do nazismo. Nessa altura, começou a estabelecer coligações para eliminar os comunistas e assim libertar a "política alemã do marxismo", aproveitando que a direita reacionária estava farta do parlamentarismo (FREI, 2003, p. 51).

Para Hitler, a chegada ao poder não era suficiente, era necessário reforçar esse poder até chegar ao poder absoluto, à ditadura. Para isso, era necessário aumentar o número de deputados no Parlamento (Reichstag), o que foi conseguido, recorrendo a estratégias manipuladoras, intimidatórias, repressivas, criando um clima de pânico e insegurança entre as várias forças políticas, com recurso dos próprios meios do Estado. Um exemplo de usurpação do poder pelos nacionais-socialistas observa-se na Prússia, através do "decreto de permissão do disparo", de 17 de fevereiro de 1933, preparado por Göring, "onde encarregava os funcionários da policia, sob ameaça de perseguição judicial, da tarefa de «lutar, usando os meios mais

\footnotetext{
${ }^{8}$ Nessa reunião, não estava presente a França porque sempre quis estrangular financeiramente a Alemanha, em prol da humilhação da Primeira Guerra e, por isso, a Alemanha não a integrou nas negociações. Para além do Plano de Dawes, existiu o Plano de Young, com a mesma finalidade, também, negociado por Hjalmar Schacht.
} 
severos, contra as atividades das organizações hostis ao Estado» [...] e de, se necessário, fazer uso irreverente da arma»" (FREI, 2003, p. 55). Com esse decreto, os partidos à esquerda do espectro político, principalmente os comunistas, ficam ainda mais vulneráveis e desprotegidos face a atividades de sabotagem, de intimidação e de assalto, levadas a cabo pela SA e pela SS. As reuniões partidárias comunistas eram quase sempre bloqueadas pelas forças da repressão, que faziam autênticos banhos de sangue.

Nesse período, a tendência foi sempre reforçar o poder da SS, da SA e dos Capacetes-de-Aço, com o objetivo de reprimir os partidos da oposição, até que ficassem enfraquecidos, temendo pela sua vida e pela vida dos seus familiares. Com a repressão, os nazistas conseguiam fazer com que os deputados abandonassem os cargos, que se exilassem ou, então, que se remetessem ao silêncio. A fragilidade política era tal que nem os relatórios policiais faziam menção aos ataques realizados às sedes comunistas (FREI, 2003).

Em fevereiro de 1933, para acabar de forma mais célere com o KPD (Partido Comunista Alemão), os nazistas incendiaram o Reichstag e colocaram a culpa nos comunistas, justificando assim uma perseguição sistemática aos elementos do KPD, o que faziam com suporte na lei, devido a um decreto emitido por ocasião do incêndio do Reichstag. Resultou na destruição, ocupação e/ou enceramento das sedes e dos centros de imprensa do KPD e na prisão dos elementos partidários e até dos próprios funcionários, enviados depois para campos de concentração destinados aos presos políticos.

Tudo isto foi um pretexto para a implementação da ditadura nacional-socialista. Com poderes de exceção, Hitler suprimiu todos os partidos políticos, exceto o Nazista, dissolveu os sindicatos, acabou com o direito de greve, eliminou o movimento operário, fechou jornais de oposição, estabeleceu censura à imprensa, implantou o medo, o receio e o terror, através da SA, SS e Gestapo, passou a perseguir os judeus e outros grupos minoritários considerados inferiores, conseguindo assim a tão desejada "uniformização da sociedade" (FREI, 2003, p.84).

De acordo com Frei (2003, p. 57), “ [...] de um momento para o outro deixou de haver o direito à liberdade pessoal, de liberdade de imprensa, de reunião e associação e o direito à inviolabilidade da propriedade de correspondência e do telefone, bem como o direito à inviolabilidade da propriedade e do domicílio". Estavam assim criadas as traves mestras do poder nacional-socialista, consubstanciadas através da “ [... ] abolição do Estado de Direito e da democracia, a eliminação do parlamentarismo, dos partidos e dos sindicatos, a «Uniformização» dos Lander e da maior parte das organizações sociais, a legalização para a discriminação dos judeus, o silêncio do espírito liberal e da esquerda, e, por fim, a censura da opinião pública" (FREI, 2003, p. 100, grifo nosso).

Para concluir esta segunda linha, é bom frisar que Hitler fazia muito bem a gestão do terror e da opressão, contrabalançando-o com medidas populistas, pontuais, com uma retórica persuasiva e com promessas socioeconômicas, de forma a garantir o apoio das massas populacionais. Assim, essa primeira fase foi marcada por uma agressividade controlada e justificada pela ânsia de poder total, mas também por muitas estratégias políticas, alicerçadas na opressão, no medo e na repressão popular. Por outro lado, como já vimos, o fato de Hindenburg falecer em 2 de agosto de 1934, permitiu a Hitler apoderar-se do título de Presidente ${ }^{9}$, que acumulou com o de Chanceler, através do qual passou a intitular-se Líder (Führer); foi um momento de sorte que facilitou o rumo em direção à consolidação do regime.

Linha 3 - consolidação do nazismo (1935 a 1938): grosso modo, só nesses quatro anos é que Hitler gozou de total liberdade para implementar os

${ }^{9}$ Legitimado no plebiscito de 19 de agosto de 1934 com 89,9\% dos votos. 
seus projetos, porque antes ainda existiam coligações que obrigavam a compromissos (se bem que nessa altura, Hitler já não pedia, ordenava). Esse terá sido o período da governação de Hitler que mais agradou o povo alemão e que se manteve até o momento em que começaram a ocorrer os bombardeamentos dos Aliados durante a Guerra.

Apesar da repressão, do terror e do medo vivido na fase anterior "formação do nazismo», Hitler era um líder carismático, um herói nacional, porque em 1936 tinha conseguido chegar ao emprego pleno, quando nos Estados Unidos a taxa de desemprego rondava os 24\% (FREI, 2003, p. 102). Não obstante, Hitler não tinha apresentado nenhuma solução nova, simplesmente foi resgatar os planos de investimento dos governos anteriores e adotou medidas keynesianas de intervenção estatal/ política na economia, através de duas formas: investimento em obras públicas, sem recurso à maquinaria, recorrendo ao trabalho manual da pá, enxada e picareta, para empregar o maior número possível e investimento em armamento (desde 1933 que se preparava para a Guerra). De facto, após a uniformização interna e a estabilização econômica, o rearmamento era a principal prioridade, e, em 1934/5, disponibilizou pela primeira vez verbas para fabricação de armamento superior a qualquer outro setor econômico (FREI, 2003, p. 105).

Mais do que gerar recursos financeiros ao proporcionar o pleno emprego, Hitler queria conquistar a consciência e o coração dos alemães, através de campanhas emocionais, de marketing político. As ilustrações públicas (vulgo cartazes de propaganda) onde Hitler aparecia a trabalhar, a dar a primeira pazada para a construção de uma estrada ou, então, a acompanhar as colunas de operários que marchavam para a construção de vias de comunicação (estradas) são exemplo desse marketing político (FREI, 2003, p. 103).

Ao suportar toda a atividade econômica, o Estado endividou-se de forma insustentada junto às principais empresas alemãs, o que gerou alguma contestação por parte de Schacht, que antes tinha negociado o Plano Dawes e o Plano de Young, na medida em o endividamento representava um gasto que não visava dinamizar o mercado, mas antes preparar a guerra, tendo como consequência uma profunda inflação num futuro próximo.

Apesar das medidas muito austeras (ex. tabelamento do preço de alguns bens alimentares), de ter forçado a permanência involuntária da população na atividade agrícola, de ter racionalizado a produção para consumo em prol de aumentar a produção de armamento bélico, etc., ainda assim, a população acreditava na comunhão nacional, o que se devia a uma poderosa máquina política que criava um sem fim de programas e ofertas que estimulavam a produção (ex. prêmios de produtividade), a saber: oferta de viagens, oferta de tratamentos de saúde a operários e familiares, ajuda financeira para aquisição de habitação (para os recém-casados) e ajuda financeira de incentivo à natalidade. Ainda mais importante, a propaganda política reforçava que a notoriedade profissional e a visibilidade individual resultava da força do trabalho e não de direitos hereditários, o que, consubstanciado, promoveu a mobilização ideológica (deixavam de existir direitos garantidos, nomeadamente os consuetudinários, e passava a ser possível a todos atingir o sucesso, bastando para isso a força do seu trabalho). No fundo, a comunhão nacional era pura propaganda, que misturava por encanto o consentimento com a obrigação da população, mas foi altamente bem-sucedida.

Apesar da mobilização da sociedade, ainda existia resistência, principalmente fora do Reich, protagonizada por exilados, o que fez aumentar a agressividade da ideologia do nacional-socialismo. No entanto, a agressividade não abrangeu só os não aptos para integrar a comunhão nacional, mas também os próprios alemães parte integrante da comunhão nacional. Aqui reside um particularismo surpreendente. Apesar do clima de insegurança, de suspeição, de pânico e receio (a situação de repressão tinha-se agravado desde 1933); apesar 
de ser evidente o início da radicalização do regime, devido à construção de novos campos de concentração (ex. Sachsenhausen e Buchenwld) e da gestão destes campos ter sido entregue aos esquadrões da morte, forças sem escrúpulos designadas «Esquadrões da Caveira da SS» (Totenkopfverbande); apesar da desnacionalização das forças policiais, para que a SS controlasse todo o sistema policial do Reich, através da fusão da polícia do Estado e da polícia judiciária com o serviço de segurança da SS, o que indicava que Himmler e Heydrich pretendiam criar uma suprainstituição, ideologicamente racista, encarregada da higiene pessoal e do saneamento continuo; apesar de todas estas situações, selecionadas entre muitas outras, Hitler era aplaudido, a sua popularidade mantinha-se e, inclusive, reunia alguma simpatia das forças políticas da oposição, exiladas, porque consideravam que, apesar de Hitler não ser solução, tinha conseguido em tempo recorde a proeza de impulsionar a economia, acabar com o desemprego e conseguir a união nacional. É difícil perceber como é que uma sociedade altamente evoluída, como era a alemã, aceitava eliminar os insociais, ou como é que poderia continuar a aplaudir o seu Führer nessas circunstâncias, porque nem tudo Hitler conseguia ocultar, a não ser que também considerasse que eram elementos desnecessários à perfeição do arianismo. ${ }^{10}$

Linha 4 - radicalização do nazismo (1938 a 1945): "O início da época nacional-socialista foi marcado pela destruição e o seu fim pela autodestruição" (FREI, 2003, p. 100). De fato, se o regime nazi no início funcionava no registo da opressão/destruição, nessa fase, funcionou no registo da autodestruição, impondo à humanidade perdas incomensuráveis. Foi a fase da radicalização, que começou com a questão judaica e com a componente racista do programa nacional-socialista relativo ao espaço vital a Leste (Lebensraum), aproveitando a guerra para "reforçar as medidas de saneamento eugênico e racial do corpo da nação alemã" (FREI, 2003, p. 154).

Desde sempre, o regime utilizou a lei para legitimar a sua autoridade totalitária. No entanto, era um totalitarismo consentido e legitimado pelas massas. Mas nesse período, com a radical viragem ideológica nas políticas interna e externa, começaram a surgir protestos, ainda que de forma tímida e localizada, e Hitler foi obrigado a demitir o Ministro da Guerra, em 1938, por esse recear o radicalismo da política externa expansionista do Reich. Isto tem que ser pensado em conjunto com outras variáveis, como o receio de uma guerra para a qual o III Reich ainda não estava preparado.

\footnotetext{
Da mesma forma que o regime nazi nunca aboliu a Constituição de Weimar, também acabou por não renunciar à legitimidade formal das suas ações ilegais. Mesmo a criação de campos de concentração foi encontrar apoio "legal" no «Decreto para a proteção do povo e do Estado [...] (FREI, 2003, p. 65). “[...]. $\mathrm{O}$ ministro da Guerra, que tinha sido demitido na base de um pretexto fútil, foi substituído por um Comando Supremo das Forças Armadas (Oberkommando der Wehrmacht - OKW)" (FREI, 2003, p. 152-153).
}

A II Grande Guerra pode ser dividida em três fases: (1) 1 de setembro de 1939 (invasão da Polônia) até abril de 1940, período em que não existiu guerra no Ocidente; (2) abril de 1940 a novembro de 1942, fase máxima de expansão do Reich; e (3) janeiro de 1943 a maio/setembro de 1945, fase da contraofensiva aliada e vitória.

Ao longo desse período, a capacidade destrutiva e radicalização do regime foi crescente e proporcional ao esforço de guerra pedido à população. Colocase a questão: porque é que a população não se manifestou? Por vários motivos, mas sobretudo porque o regime foi perspicaz e interiorizou na população uma série de esperanças no campo da política social que deveriam acontecer no período do pós-guerra, quando os alemães ganhassem a guerra. Inclusive, em 1939, Hitler decretou o extermínio em massa de cerca de 70 mil deficientes

\footnotetext{
${ }^{10}$ Referimo-nos a vagabundos, mendigos com ou sem residência fixa, ciganos, indivíduos presos algumas vezes por resistência, lesão corporal, rixa, perturbação da ordem pública, etc.
} 
físicos e mentais, através do programa Aktion 4. Apesar de o ter feito de forma camuflada, surgiram fortes indícios no seio da população alemã do que se estava a passar, mas a população, apesar de ficar incomodada, não reagiu.

Para uma sociedade evoluída como era a alemã, aceitar que uma determinada vida humana não é útil porque não produz e aceitar uma declaração administrativa para a sua eliminação é algo aterrador, inclusive para os próprios alemães, na medida em que, nessa perspetiva também, os idosos alemães, apesar de pertencerem à raça ariana, podiam ser considerados inativos, já que também eles não trabalhavam. Esta situação só pode ser explicada através da admiração, crédito e confiança que os alemães tinham pelo Führer, devido às sucessivas vitórias até ao verão de 1941 (com as triunfais Blitzkriege, a Wehrmacht submeteu, sucessivamente, a Polónia, a Dinamarca e a Noruega, os Países Baixos, o Luxemburgo, a Bélgica, a França e, finalmente, a Iugoslávia e a Grécia) (FREI, 2003, p. 160).

Depois de 1943/44, o regime perdeu a noção da realidade e avançou para a germanização total, massacrando completamente as áreas ocupadas, exterminando populações e destruindo cidades. Reforçou o investimento em experiências, com vista ao eugenismo, totalmente desumanas, e deixou morrer por fome, excesso de trabalho e falta de saúde os indivíduos encarcerados nos campos de concentração, etc.

Quando o regime proclamou a guerra total, o que fez duas vezes (fevereiro de 1943 e julho 1944), o esforço pedido aos alemães foi de tal forma duro que as expectativas começaram a desvanecer-se. Posteriormente, em outubro de 1944, depois do atentado ao seu quartel-general, Hitler nomeou o Ministro da Propaganda como «plenipotenciário para os esforços para a guerra total», e fez saber que não era necessário respeitar as bases para a sobrevivência do povo alemão. A ação de Goebbels foi a mobilização de todos os homens entre os 16 e os 60 anos considerados aptos no uso de uma arma e, depois também, as mulheres e crianças foram obrigadas a prestar serviço. Tal como refere Norbert Frei, "o regime tinha atingido a fase final da demência” (FREI, 2003, p. 206).

\section{Caracterização do Estado Social- Nacionalista por Norbert Frei}

Procuramos fazer uma caracterização do Estado Social-Nacionalista com fundamento nas linhas exploradas anteriormente que espelham o referido na obra de Norbert Frei.

O Estado nacional-socialista procurou sempre duas situações: uma forte propaganda política, que era altamente demagógica, de forma a levar os alemães a aderir à comunhão nacional, para depois fazer uma limpeza racial e uma "guerra de destruição, travada com uma dureza impiedosa, com o objetivo de criar a base territorial para um grande império germânico oriental, no qual os alemães assumiriam o papel de senhores de «raça pura»" (FREI, 2003, p. 154).

Norbert Frei considera o Estado nacionalsocialista totalitário, apostado no primado da monopolização política e econômica, na censura, repressão e na manipulação, obstinado no eugenismo, mas indica que esse não pode ser analisado só do ponto de vista do crime ideológico, mas através de uma abordagem diferenciadora, dando atenção à história política e social:

\begin{abstract}
A vida quotidiana do III Reich não era dominada pela alternância, mas pela simultaneidade permanente da tentação e da obrigação, da sedução e do crime, das ofertas de integração e ameaças de terror. O comportamento das pessoas era marcado pelas mesmas flutuações e contradições: a aceitação da política do regime e o apoio ativo às suas medidas - por exemplo, no sector econômico - podiam andar lado a lado com uma rejeição aberta de certos princípios ideológicos básicos (FREI, 2003, p. 228).
\end{abstract}

As fragilidades econômicas, sociais e políticas da Alemanha nas décadas de 20 e 30 do século 
XX criaram o espaço necessário para a emersão do nacional-socialismo. Inicialmente, com o apoio do patronato da direita (poder econômico), que queria aniquilar sindicatos e outras formas de protesto social, para organizar e controlar inteiramente a classe trabalhadora, e, posteriormente, por toda a sociedade, após o milagre da recuperação econômica e do pleno emprego. Inclusive, no extremo, não será abusivo dizer que os partidos políticos ostracizados, perseguidos, aniquilados, exilados (ou o que restava deles), consideravam que Hitler tinha uma atuação criminosa mas não negavam que tinha conseguido, num curto espaço de tempo, uma proeza inigualável, nomeadamente ao conseguir a "comunhão nacional".

As massas populares eram hipnotizadas pelo poder de fascínio da oratória Hitleriana, onde os sons eram sempre acompanhados por uma forte gestualidade, em ambientes produzidos especialmente para a ocasião, por exemplo, na escolha dos locais, do período do dia, da iluminação e da ornamentação (ex. símbolos identitários nacionalistas), na duração da comunicação, etc., de forma a evidenciar o poder nacional-socialista, como se pode ler na citação seguinte:

Quando, num ponto culminante, se balança de um lado para o outro, os ouvintes se balançam com ele. Quando se inclina para a frente os ouvintes também o fazem e quando termina, estão reverentes e silenciosos ou de pé em delírio, como Hitler quiser (STANLEY HIGH apud DANCUR, 2009, p. 17).

As palavras desempenham uma função mágica, não pelo seu significado mas pela natureza das suas vibrações sonoras. Hitler sabia perfeitamente como atuar e também sabia, porque tinha aprendido com a Igreja Católica, que a repetição de determinadas expressões permite a sua penetração nos níveis mais profundos da mente humana. Por outro lado, Hitler não sabia, ou não queria saber, que esta ação mágica pode ser muito eficaz, mas não é infinita, nomeadamente quando se esbate contra a natureza; e nada mais contraditório da natureza e do senso comum do que a ideia de uma raça superior dominando todas as outras durante os mil anos que duraria o III Reich. ${ }^{11}$

Norbert Frei diz-nos que Hitler acreditava sinceramente que os alemães (arianos) eram uma raça superior destinada a dominar as raças inferiores (judeus, negros, eslavos, etc.). Segundo Mello e Costa (1995, p. 247), que citam o próprio Hitler, essa é uma observação realista: "Aqueles que governam devem saber que têm o direito de governar porque pertencem a uma raça superior". Compreendemos que, para Hitler, os alemães deveriam governar e os restantes países do continente europeu (de raça inferior) deveriam ser governados.

Podemos ainda perceber que o nacionalsocialismo era algo bem maior e bem mais complexo do que uma ideia efêmera, de momento, fortuita, antes pelo contrário, era uma ideologia defendida pelo Führer, consistente e sustentada, com apoio de parte da população e dos elementos que constituíam o partido NSDAP ${ }^{12}$, e beneficiou de um antissemitismo já enraizado na população alemã. Este poder legitimou a limpeza racial da Europa, colocando a questão como se tratasse de um sacrifício pelo bem da humanidade, cuja responsabilidade coubesse à grande Alemanha.

Como já referimos anteriormente, no âmbito do golpe que ficou conhecido pelo "Putsch da Cervejaria", Hitler, enquanto esteve preso, escreveu o livro intitulado Mein Kampf, onde referiu as linhas mestras do que seria a Alemanha dirigida pelo nacional-socialismo. Os alemães sabiam o que Hitler pensava, o que queria fazer e como fazer. No entanto, talvez por acreditarem que eram propósitos irrealizáveis, ignoraram a ameaça. A verdade é que, de forma faseada, Hitler cumpriu tudo o que tinha inscrito no livro, nomeadamente em relação à obsessão pela eugenia, ou ideologia da pureza racial, que culminou no Holocausto.

O primeiro ato de um «processo de purificação» que, em tempos de paz, tinha sido levado a cabo através das leis sobre a esterilização e o casamento saudável, mas que com a guerra podia ser realizado de forma radical (FREI, 2003, p. 166).

\footnotetext{
${ }^{11}$ Apesar do nacionalismo, militarismo, corporativismo, expansionismo, anticomunismo e racismo.

${ }^{12}$ Partido Nacional Socialista dos Trabalhadores Alemães (NSDAP). Em alemão: Nationalsozialistische Deutsche Arbeiterpartei
} 
Hitler estava certo de que a raça alemã era superior, e só na evidência da derrota da guerra reconheceu que os alemães não eram a raça superior que deveria governar o Continente Europeu. Hitler considerava que o seu destino estava ligado ao destino da Alemanha; a desaparecer deveriam ser os dois.

«Se a guerra for perdida, o povo estará também perdido. Esse destino é inevitável». Por isso Hitler declarou ao seu ministro do armamento, «não era necessário respeitar as bases que o povo alemão precisa para a sobrevivência mais elementar». Antes pelo contrário, em caso de emergência seria melhor destruir tudo porque «o povo se teria relevado o mais fraco e, nesse caso, o futuro pertencia exclusivamente ao povo mais forte, ao povo do Leste» (FREI, 2003, p. 207).

A passagem supra, a mais forte do texto de Norbert Frei, enfatiza a crença de Hitler na persecução dos seus objetivos e revela a sua desilusão, quando percebe que afinal os seus objetivos perderam a razão de ser, porque o povo de Leste seria mais forte, deveria governar, e os alemães é que deveriam ser os governados.

\section{Reflexão Final}

A II Guerra Mundial foi e continua a ser muito estudada, e o referencial teórico e o estado de arte é muito extenso, o que se justifica pelo fato de não poder ser analisada de forma isolada no tempo, porque representou um segundo episódio, cuja primeira parte foi a Grande Guerra de 1914-1918, e sobretudo por ter sido o maior e mais sangrento conflito armado da história planetária, que ocorreu no mesmo século em que ocorreram os maiores avanços técnicos e científicos da história da humanidade.

Os problemas políticos e territoriais europeus não resolvidos na I Guerra Mundial só se agravaram depois do Tratado de Versalhes. A Alemanha empobrecida e humilhada foi presa fácil para as propostas políticas extremistas do Partido Nacional-
Socialista. Adolf Hitler conseguiu arrastar um país inteiro que tinha sido uma grande potência e exemplo de civilização para um projeto absurdo e louco desde o início, a conquista imperial da Europa. A grande Alemanha teria que ser o centro industrial da Europa, onde estava a tecnologia pertencente a uma raça superior, e restantes países europeus deveriam ser colônias da Alemanha, produzindo as matérias-primas que suportavam a indústria alemã. No entanto, Hitler aceitava dividir com a Inglaterra o domínio do Mundo: Alemanha controlava a Europa e a Inglaterra tinha o poder imperial na África e Ásia.

Na obra $O$ Estado de Hitler: o poder nacionalsocialista de 1933 a 1945, é dado maior enfase aos "anos de formação" do nacional-socialismo entre 1933 e 1934. Aliás, através de uma análise mais detalhada e em jeito de comparação, as outras fases do regime nazista foram tratadas de forma superficial em relação a esta. Por outro lado, como a obra se debruça primeiramente sobre o desenvolvimento interno do Terceiro Reich, a política externa é, portanto, maioritariamente excluída.

Não obstante, o mérito do autor é extenso, desde logo, por ser um investigador que procura a evolução do conhecimento, aproximando a investigação do ensino, em um nível interdisciplinar e internacional (participação no programa Theodor Heuss). Mas esse mérito é ainda maior na obra em análise: primeiro, por resumir de forma soberba a multiplicidade de eventos e processos complexos na alemanha hitleriana, entre 1933 e 1945, e por fundamentar de forma precisa a informação que dá a conhecer neste trabalho; segundo, por procurar compreender o nacional-socialismo sem cair em radicalismos, em abusos ou estigmatismos.

Norbert Frei abre o conhecimento e expõe claramente que não é, e nunca foi, um historiador refém de um passado que, durante muitos anos, foi incomodativo para muitos alemães, sobretudo para os mais antigos, que sempre tentaram ocultar as suas atitudes durante o Terceiro Reich. Aliás, 
atitudes que eles próprios consideram vergonhosas, só "toleradas" por terem ocorrido enquanto estavam a viver uma realidade muito bem fantasiada por Hitler, mas ainda assim atitudes recentemente caracterizadas como criminosas por Conze et al. (2010) e Neitzel e Welzer (2011).

\section{Referências}

BRADLEY, Catherine. Hitler e o terceiro Reich. Trad. de Manuela Cruz. Rio Tinto: ASA, 1990.

CLAUSEWITZ, Carl Von. Da guerra. São Paulo: Martins Fontes, 2003.

CONZE, Eckart.; FREI, Norbert.; HAYES, Peter.; ZIMMERMANN, Moshe. Das Amt und die Vergangenheit. Deutsche diplomaten im dritten reich und in der Bundesrepublik. München: Karl Blessing Verlag, 2010.

COUTO, Joaquim Miguel; HACKL, Gilberto. Hjalmar Schacht e a economia alemã (1920-1950). Economia e Sociedade, Campinas, v. 16, n. 3, p. 311-341, dez. 2007.

DANCUR, Eliane Calixto Paiva. Café com o presidente: o programa de radiojornalismo com o presidente lula. 2009. Dissertação (Mestrado Comunicação) -Faculdade Cásper Líbero, São Paulo. Disponível em: <http://www.casperlibero. edu.br/rep_arquivos/2010/02/01/1265049162.pdf>. Acesso em: 3 maio 2012.

EVANS, Richard. Ascenso y triunfo del Nazismo en Alemania. In: CABRERA, Mercedes; JULIÁ, Santos; ACEÑA, Pablo Martin. Europa en crisis (1919-1939). Madrid: Pablo Iglesias, 1991. p. 97118.

GALLEGO, Ferran. Os homens do Fuhrer. a elite do nacional-socialismo (1919-1945). Tradução de Carlos Aboim de Brito. Lisboa: Esfera dos Livros, 2009.

JORDAN, David; WIEST, Andrew. Atlas da segunda guerra mundial: as duas frentes de batalha. Tradução de Tatiana Napoli. São Paulo: Escala, 2008.
KEEGAN, John. Uma história da guerra. São Paulo: Companhia das Letras, 2006.

LEITE, Rodrigo. Exposição em Berlim aborda popularidade de Hitler durante o nazismo. 2010. Disponível em: <ttp://direitoufersa.blogspot. com/2010/10/hitler-e-sociedade-alema-espera-deum.html>. Acesso em: 19 abr. 2012.

MARTINS, Estevão de Rezende. Historiografia no século 20. In: MALERBA, Jurandir; ROJAS, Carlos Aguirre (Org.). Historiografia contemporânea em perspectiva crítica. São Paulo: EDUSC, 2007. p. 59-63.

MELLO, Leonel; COSTA, Luis Cesar Amad. História moderna e contemporânea. 5. ed. São Paulo: Scipione, 1995.

NEITZEL, Sonke; WELZER, Harald. Soldaten: Protokolle vom Kämpfen, Töten und Sterben.3. ed. Frankfurt: S. Fischer Verlag, 2011.

PARKER, Robert Alexander Clarki. Struggle for survival: the history of second world war. New York: Oxford University Press, 1989.

. História da II guerra mundial. Tradução de Maria João Freire. 3. ed. Lisboa: Edições 70, 2006. Título Original: Struggle for survival: the history of second world war.

TOUCHARD, Jean. (Dir.) História das ideias políticas. Lisboa: Publicações Europa-América, 1991. v. 4.

TRAVERSO, Enzo. La violence nazie: une généalogie européenne. Paris: La Fabrique, 2002.

ZALOSA, Steven. A invasão da Polônia: Guerra Relâmpago. Barcelona: RBA Coleccionables, 2009. 
